\title{
PEMEROLEHAN MORFEM AFIKS BAHASA INDONESIA ANAK USIA 2-6 TAHUN DI PAUD BUANA DESA BANYU URIP KABUPATEN LOMBOK TENGAH
}

\author{
M. Aris Akbar \\ Universitas Mataram \\ muhammadarisakbar@gmail.com
}

\begin{abstract}
Abstrak
Penelitian ini bertujuan untuk mengetahui pemerolehan morfem afiks yang mencakup prefiks, infiks, sufiks, simulfiks, dan konfiks dalam bahasa Indonesia di PAUD Buana Kabupaten Lombok Tengah. Penelitian ini bersifat deskriptif kualitatif dengan melibatkan 30 anak sebagai sampel. Teori yang digunakan dalam menganalisis fenomena pemerolehan morfem adalah teori morfologi. Data dikumpulkan dengan metode wawancara, observasi, pencatatan dokumen, dan tebak gambar. Berdasarkan analisis, temuan penelitian ini adalah anak-anak di PAUD Buana hanya bisa mengucapkan kata-kata yang dibentuk dari bentuk dasar yang dilekatkan dengan prefiks $\{\mathrm{N}-\},\{b \ll r-$ \} , $\{\mathrm{t} \ll \mathrm{r}-\}$. Infiks yang dilibatkan dalam membentuk kata turunan adalah $\{-\ll \mathrm{l}-\}$ dan $\{-\ll \mathrm{m}-\}$, seperti dalam/telunjuk/ dan /gemetar/. Sufiks $\{$-an $\}$ adalah sufiks yang paling dominan dipergunakan oleh anak-anak usia 2-6 tahun. Uniknya, sufiks $\{-i\}$ telah menjadi $\{-i n\}$ dalam kata-kata yang diucapkan oleh mereka, seperti kata /ikatin/, //beliin/, /mandiin/, dan seterunya. Dalam penelitian ini, tidak ditemukan data yang memunculkan kata-kata yang berbentuk simulfiks dan konfiks. FS.
\end{abstract}

Kata Kunci: afiks, morfologi, dan pemerolehan bahasa

\begin{abstract}
The main aim of this study is to described affix morphem acquisition which involved prefix, infix, and suffix in Indonsian language particulary at PAUD Buana - Central Lombok District. The characteristic of this study is qualitative descriptive which involvement 30 child as sample. Theory that applied with in phenomenon analyzed was morphology acquisition. Data collected pass through interview, observation, documentary, and pictures guessing. Based on analysis, novelty of this research are childreen at PAUD Buana has ability to produce some words by means of morphems affix, such as $\{N-\},\{b \ll r-\},\{t \ll r-\},\{p \ll N-\}$ attached to base morphem. In infix level, children has ability to produce some words by means of morphems affix, such as $\{-\ll l-\}$ and $\{-\ll m-\}$, e.g. Itelunjuk/ and / gemetar/. Suffix \{-an\} is a dominant that produced by children whom 2-6 years old. Uniqueness, suffix $\{-i\}$ has become \{-in\}in words, e.g /ikatin/, /tidurin/, /mandii/, and so on. No evidence about simulfix and confix data.
\end{abstract}

Keywords: affix, morphology, and Language acquisition

\section{PENDAHULUAN}

Setiap bayi yang lahir ke dunia, orang yang paling diakrabi oleh si bayi adalah ibu yang melahirkannya ke dunia. Selama kurang lebih dua tahun, si bayi pun "menggantungkan kelangsungan hidupnya" dengan meminum air susu ibunya. Setiap anak yang lahir telah dilengkapi oleh sejumlah kapasitas atau potensi bahasa. Potensi bahasa ini akan berkembang apabila saatnya tiba. Setiap anak yang lahir juga telah dilengkapi dengan alat yang disebut LAD (Language Acquisition Device) yang diterjemahkan di sini menjadi Piranti Pemerolehan Bahasa (PPB). Perkembangan bahasa anak bukan suatu proses yang ber- 
langsung sedikit demi sedikit pada struktur bahasa yang tidak benar, dan juga bukan proses awal yang banyak salahnya jika dibandingkan dengan proses orang dewasa. Melainkan suatu proses yang bersistem yang terbentuk dari kelengkapankelengkapan bawaan ditambah dengan pengalaman anak ketika ia melaksanakan sosialisasi diri. Kelengkapan bawaan ini diperluas, dikembangkan, bahkan diubah sehingga perkembangan bahasa itu maksimal.

Pendidikan anak usia dini (PAUD) adalah suatu upaya pembinaan yang ditujukan kepada anak sejak lahir sampai dengan usia enam tahun yang dilakukan melalui pemberian pendidikan awal untuk membantu pertumbuhan dan perkembangan jasmani dan rohani agar anak memiliki kesiapan dalam memasuki pendidikan lebih lanjut. Interaksi yang terjadi dalam PAUD antara pendidik dan peserta didik, peserta didik dengan peserta didik lain merupakan proses komunikasi yang unik. Setiap peserta didik yang berbeda usia tentu memiliki perbedaan dalam hal berkomunikasi dan berbahasa. Perbedaan kemampuan berbahasa dalam hal perkembangannya merupakan hal yang alamiah.

Keunikan dalam hal pemerolehan bahasa anak dan pembelajaran bahasa Indonesia pada PAUD merupakan sebuah fenomena yang layak menjadi kajian. Apakah pembelajaran bahasa Indonesia pada PAUD sesuai dengan tingkat pemerolehan bahasa anak di bawah usia enam tahun? Tentu saja hal ini akan dapat dijawab dengan melakukan kajian terhadap pemerolehan bahasa anak usia dini pada PAUD sebagai salah satu lembaga pembinaan anak usia Dini. Atas dasar pertanyaan-pertanyaan tersebut di atas, sehingga kajian "Pemerolehan Morfem Afiks Bahasa Anak Usia 2-6 Tahun Di PAUD Buana Desa Banyu Urip Kabupaten Lombok Tengah" patut dilakukan dalam hubungannya dengan salah satu bidang kajian kebahasaan, yakni Morfologi.

\section{KONSEP DAN LANDASAN TEORI KONSEP}

Sesuai dengan masalah utama penelitian ini adalah pemerolehan bahasa anak khususnya pemerolehan morfem afiks, yang berwujud prefiks, infiks, dan sufiks pada satuan lingual berupa bentuk dasar yang menyebabkan perubahan makna gramatikal satuan yang dilekatinya.

\section{TEORI}

Teori behaviorisme memiliki ide pusat bahwa pemerolehan bahasa adalah suatu proses belajar, dalam hal ini stimuli verbal dan nonverbal dari luar membentuk kondisi untuk proses belajar itu. Dalam linguistik Chomsky, tekanan tidak lagi jatuh pada faktor-faktor lingkungan, tetapi pada 
kemampuan lahiriah seorang anak untuk belajar suatu bahasa. Kelakuan bahasa jauh lebih rumit untuk dapat dijelaskan sematamata atas dasar faktor-faktor luar yang mempengaruhi seseorang.

Kemampuan lahiriah yang memungkinkan setiap manusia belajar bahasa apapun dinamakan language acquisition device (LAD), yang berarti perlengkapan pemerolehan bahasa. Isu sentralnya adalah perbedaan Struktur Batin dan Struktur Lahir pada kalimat. Kedua struktur tersebut saling berhubungan melalui Transformasi. Setiap kalimat mempunyai struktur abstrak di bawah permukaannya dan LAD memungkinkan anak menyusun hipotesis tentang struktur bawah bahasa yang diperoleh. Anak tidak sadar akan proses ini.

Dalam kaitannya dengan akusisi morfologi, terdapat tiga kaidah sebagaimana dikemukakan oleh Booij (2007).Tiga langkah akusisi morfologi ini telah diperdebatkan dalam paper klasik Berko (1958 dalam Booij, 2007). Tahapan pertama, anakanak mempelajari sejumlah bentuk-bentuk kala lampau verba bahasa Inggris secara gamblang. Karena produksi mereka ihwal bentuk-bentuk kala lampau verba-verba reguler dan non-reguler (asked, went) benar. Dalam langkah kedua, anak-anak memperoleh kaidah bentuk-bentuk kala lampau dalam bahasa Inggris, tapi juga akan menerapkan kaidah tersebut pada ke- las verba-verba yang nonreguler. Karena itu, mereka akan menghasilkan bentuk berterima (benar) asked, tetapi bentuk salahnya goed sebagai ganti bentuk went, suatu kasus/masalah generalisasi berlebih (overgeneralization). Dalam langkah ketiga, kedua langkah tadi serta seperangkat pengecualian telah didapatkan, dan kemudian anak-anak akan menghasilkan asked dan went, sehingga mempelajari proses kurva-U: sejumlah verba-verba kala lampau yang benar dalam langkah I dipotong dalam langkah II, dan disambung kembali dalam langkah III. Kurva pembelajaran ini telah ditemukan dalam banyak bahasa.

PEMBAHASAN

PEMEROLEHAN MORFEM AFIKS PREFIKS ANAK USIA 2-6 TAHUN DI PAUD BUANA

Prefiks $\{\boldsymbol{n}-\}$

Dalam hubungannya dengan prefiks $\{\mathrm{y}$ -\}, berdasarkan data yang berhasil dijaring selama penelitian di lapangan, ditemukan sebanyak empat belas kata bentukan yang dihasilkan oleh anak-anak di PAUD Buana. Kata-kata bentukan yang dimaksud adalah / ngadu/, /nganter/, /ngambil/, /ngintip/, / ngantuk/ /ngasih/, /ngolok/, /ngikut/, / nginjak/, /ngambek/, /ngalah/, /ngirim/, / ngawasin/, dan /ngurusin/. yang secara ber 
urut-turut dapat dijelaskan proses morfolo-

gisnya sebagai berikut

\begin{tabular}{|c|c|c|c|c|}
\hline No & Prefiks & BD & Mekanisme Pembentukan & $\begin{array}{c}\text { Hasil Kata Ben- } \\
\text { tukan }\end{array}$ \\
\hline 1 & $\{\mathrm{y}-\}$ & /adu/ & {$[\mathrm{y}-+$ [adu $]$} & /ngadu/ \\
\hline 2 & $\{y-\}$ & /anter/ & $[\mathrm{y}-+$ [anter $]]$ & /nganter/ \\
\hline 3 & $\{y-\}$ & /ambil/ & {$[\mathrm{y}-+[$ ambil $]]$} & /ngambil/ \\
\hline 4 & $\{\mathrm{y}-\}$ & /intip/ & {$[\mathrm{y}-+[$ intip $]]$} & /ngintip/ \\
\hline 5 & $\{y-\}$ & /kantuk/ & {$[\mathrm{y}-+[$ kantuk $]]$} & /ngantuk/ \\
\hline 6 & $\{\mathrm{y}-\}$ & $/ \mathrm{kasih} /$ & {$[\mathrm{y}-+[$ kasih $]]$} & /ngasih/ \\
\hline 7 & $\{y-\}$ & /olok/ & {$[\mathrm{y}-+[$ olok $]]$} & /ngolok/ \\
\hline 8 & $\{y-\}$ & /ikut/ & {$[\mathrm{y}-+[$ ikut $]]$} & /ngikut/ \\
\hline 9 & $\{y-\}$ & /injak/ & {$[\mathrm{y}-+[$ injak $]]$} & /nginjak/ \\
\hline 10 & $\{\mathrm{y}-\}$ & /ambek/ & {$[\mathrm{y}-+$ [ambek]] } & /ngambek/ \\
\hline 11 & $\{y-\}$ & $/ \mathrm{kalah} /$ & {$[\mathrm{y}-+[$ kalah $]]$} & /ngalah/ \\
\hline 12 & $\{y-\}$ & /irim/ & {$[\mathrm{y}-+[$ kirim $]]$} & /ngirim/ \\
\hline 13 & $\{y-\}$ & /awasin/ & {$[\mathrm{y}-+$ [awas] + -in] } & /ngawasin/ \\
\hline 14 & $\{y-\}$ & /urusin/ & {$[\mathrm{y}-+$ [urus] + -in] } & /ngurusin/ \\
\hline
\end{tabular}

Proses morfologis di atas bermula dari pelekatan satuan afiks tertentu dalam hal ini $\{\mathrm{y}\}$ tidak lain adalah sebuah peristiwa di dalam menghasilkan kata. Hal ini sesuai dengan yang dikemukakan Subroto (dalam Dardjowidjojo, 1983:268) bahwa ada kekaburan mengenai istilah kata sehingga Matthews (1974), dalam hal ini membedakan pengertian kata sebagai berikut: a) kata adalah apa yang disebut kata fonologis atau ortografis, b) kata adalah apa yang disebut leksem, dan c) kata adalah apa yang disebut kata gramatikal. Selanjutnya, Subroto menjelaskan bahwa kata menurut pengertian (a) semata-mata didasarkan atas wujud fonologis atau wujud ortografisnya, sedangkan kata menurut pengertian (b) dan (c) berhubungan dengan konsep derivasi dan infleksi, sehingga apabila kita berbicara mengenai konsep leksem tidak bisa dipisahkan dari konsep derivasi dan infleksi.

\section{Prefiks $\{\mathbf{P} \ll \mathbf{n}-\}$}

\begin{tabular}{|c|c|c|c|c|}
\hline $\mathbf{N}$ & Prefiks & BD/Kata & Frase/ Kalimat & Tanggal/bulan/ \\
\hline 1 & $\{$ Pəท- $\}$ & /pengojek/ & \#pengojek di pojok cekolah\# & 28 Oktober 2014 \\
\hline 2 & $\{$ Pəท- $\}$ & /penunggu/ & \#penunggu sekolah\# & 22 Oktober 2014 \\
\hline
\end{tabular}


Pemerolehan prefiks $\{$ Pə円- $\}$ anak usia 2-6 tahun di PAUD Buana ditemukan sebanyak 2 kata bentukan seperti dalam data \# penunggu sekolah\# dan \#pengojek di pojok cekolah\# sebagaimana terdeskripsikan dalam tabel berikut ini.

\section{Prefiks $\{\mathbf{M} \ll \mathbf{n}-\}$}

Pemerolehan prefiks $\{\mathrm{M} \ll \mathrm{y}-\}$ anak usia 2-6 tahun di PAUD Buana ditemukan hanya satu kata bentukan seperti dalam da-

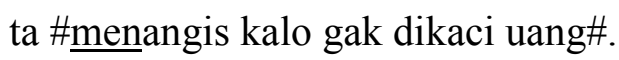

\section{Prefiks $\{\mathbf{t} \ll \mathbf{r}-\}$}

Pemerolehan prefiks $\{\mathrm{t} \ll \mathrm{r}-\}$ anak usia 2-6 tahun di PAUD Buana ditemukan hanya satu kata bentukan seperti dalam data \#te[r]lambat kita sekolah\#.

\section{Prefiks $\{\mathbf{b} \ll \mathbf{r}-\}$}

Pemerolehan prefiks $\{$ be «r- $\}$ anak usia 2-6 tahun di PAUD Buana ditemukan hanya satu kata bentukan seperti dalam data \#belajar sama ibu\#.

\section{PEMEROLEHAN MORFEM AFIKS INFIKS ANAK USIA 2-6 TAHUN DI PAUD BUANA}

Pemerolehan morfem afiks yang berwujud infiks (sisipan) pada anak usia 2-6 tahun tidaklah sebanyak yang ditemukan dalam peristiwa pemunculan morfem afiks prefiks (awalan). Fakta ini memang tidak bisa dihindari karena di dalam bahasa Indonesia hanya dikenal tiga jenis infiks, yakni $\{-\ll 1-$ \},$\{-ə r-\}$, dan $\{-\partial m-\}$. Dari ketiga jenis infiks tersebut, hanya dua yang ditemukan di dalam penelitian, yakni $\{-\ll 1-\}$ dan $\{-$ om- $\}$ sebagaimana dideskripsikan dalam tabel berikut ini

\begin{tabular}{|l|l|c|c|l|}
\hline No & Infiks & Kata & $\begin{array}{c}\text { Bentuk } \\
\text { Dasar } \\
\text { (BD) }\end{array}$ & \\
\hline 1 & $\{-\ll 1-\}$ & $/$ & $/$ tunjuk/ & {$[\mathrm{t}+[-\ll 1-] /$ unjuk/ $]$} \\
& & $\begin{array}{c}\text { telun- } \\
\text { juk/ }\end{array}$ & & \\
\hline 2 & $\{-$ - -$\}$ & - & - & \\
\hline 3 & $\{-$ om- $\}$ & $/$ & $/ g e t a r /$ & {$[\mathrm{g}+[-\ll \mathrm{m}-] /$ etar/ $]$} \\
& & gemet & & \\
& & ar/ & & \\
\hline
\end{tabular}


Kemunculan kata bentukan /telunjuk/ [t«lunjU?] dan /gemetar/ [g«m«tar] dalam kaitannya dengan pemerolehan bahasa (morfologi) dalam kajian ini tidak terlepas dari metode dan teknik yang penulis gunakan selama penjaringan data. Metode yang penulis gunakan adalah wawancara tak terstruktur yang berkaitan dengan pengenalan organ-organ atau anggota tubuh manusia. Kemunculan data /telunjuk/ [ $\mathrm{t} \ll$ lunjU?] misalnya, penulis menggunakan teknik pancing disertai dengan peraga menghitung jari-jemari mulai dari kelingking, jari manis, dan jari tengah. Penulis menanyakan kepada mereka (anak-anak) kelanjutan nama jari setelah jari tengah. Jawaban mereka adalah /jari telunjuk/. Hal yang sama dilakukan untuk memunculkan kata bentukan /gemetar/ $[\mathrm{g} \ll \mathrm{m} \ll \operatorname{tar}]$.

\section{PEMEROLEHAN MORFEM AFIKS} SUFIKS ANAK USIA 2-6 TAHUN DI PAUD BUANA

Dalam penelitian ini, ditemukan empat jenis sufiks, yakni $\{-$ an $\},\{-i\},\{-$ in $\}$, dan $\{-$ kan\} sebagaimana dideskripsikan dalam tabel di bawah ini.

\begin{tabular}{|c|c|c|c|}
\hline No & Prefiks & BD/Kata & Frase/ Kalimat \\
\hline \multirow[t]{9}{*}{1} & $\{-\operatorname{an}\}$ & /sekolahan/ & \# Sekolahan kita jauh\# \\
\hline & $\{-a n\}$ & /mainan/ & \#ayah beliin mainan\# \\
\hline & $\{-\operatorname{an}\}$ & /ayunan/ & \#suka ayunan\# \\
\hline & $\{-\operatorname{an}\}$ & /plosotan/ & \# main plosotan\# \\
\hline & $\{-\operatorname{an}\}$ & /sarapan/ & \#sarapan pagi\# \\
\hline & $\{-a n\}$ & /minuman/ & \#bawa minuman\# \\
\hline & $\{-\operatorname{an}\}$ & /besaran/ & \#besaran adek\# \\
\hline & $\{-\operatorname{an}\}$ & /kotoran/ & \#kotoran baju kita\# \\
\hline & $\{$-an $\}$ & /gambaran/ & \#gambaran sifa bagus\# \\
\hline 2 & $\{-\operatorname{kan}\}$ & /ajarkan/ & \#Bu guru ajarkan doa\# \\
\hline \multirow[t]{7}{*}{3} & $\{-i\}$ & /sayangi/ & \#Bu guru marahi kita\# \\
\hline & $\{-i\}$ & /marahi/ & \#Bapak marahi kita\# \\
\hline & $\{-$ in $\}$ & /temenin/ & \#bibi temenin main\# \\
\hline & $\{-$ in $\}$ & /mandiin/ & \#ibu yang mandiin\# \\
\hline & $\{-$ in $\}$ & /ikatin/ & \#ayah ikatin sepatu kita\# \\
\hline & $\{-$ in $\}$ & /bangunin/ & \#bibi suka bangunin\# \\
\hline & $\{-$ in $\}$ & /pasangin/ & \#ibu pasangin baju\# \\
\hline
\end{tabular}

\section{SIMPULAN}

Berdasarkan analisis di atas dapat disimpulkan hal-hal berikut ini.

1. Dalam hubungannya dengan prefiks $\{y$ \}, ditemukan sebanyak empat belas kata bentukan seperti: /ngadu/, / nganter/, /ngambil/, /ngintip/, ngantuk//ngasih/, /ngolok/, /ngikut/, / nginjak/, /ngambek/, /ngalah/, ngirim/, /ngawasin/, /ngurusin/. 
Pemerolehan prefiks $\{$ Pəy- $\}$ ditemukan sebanyak dua kata bentukan seperti dalam data \# penunggu sekolah\# dan \#pengojek di pojok cekolah\#. Pemerolehan prefiks $\{\mathrm{M} \ll$ -\} ditemukan hanya satu kata bentukan seperti dalam data \#menangis kalo gak dikaci uang \#. Pemerolehan prefiks $\{\mathrm{t} \ll \mathrm{r}-\}$ ditemukan hanya satu kata bentukan seperti dalam data \#te [r]lambat kita sekolah\#. Pemerolehan prefiks $\{\mathrm{b} \ll \mathrm{r}-\}$ ditemukan hanya satu kata bentukan seperti dalam data \#belajar sama ibu\#.

2. Kaitannya dengan infiks, dalam penelitian ini hanya ditemukan dua infiks, yakni $[\{-\ll 1-\}$ dan $\{-\ll m-\}]$ seperti dalam data /telunjuk/ dengan bentuk dasar (BD) /tunjuk/ dan / gemetar/ dengan bentuk dasar (BD) / getar/.

3. Dalam hubungannya dengan pemerolehan sufiks, dalam penelitian ini berhasil ditemukan penggunaan morfem afiks sufiks $\{-a n\}$ (sebanyak sembilan kata bentukan: / sekolahan/ , /mainan/, /ayunan/, / plosotan/, /sarapan/, /minuman/, / besaran/, /kotoran/, dan gambaran.), dua kata bentukan yang mengandung sufiks $\{-\mathrm{i}\}$ seperti dalam/sayangi/ dan /marahi/; lima kata bentukan yang mengandung sufiks $\{$-in $\}$ seper- ti dalam /temenin/, /mandiin/, / ikatin/, /bangunin/, dan /pasangin/; dan satu kata bentukan yang mengandung sufiks $\{-k a n\}$ seperti dalam / ajarkan/.

\section{UCAPAN TERIMA KASIH}

Penulis mengucapkan terima kasih kepada Mitra Bestari yang telah memberikan masukan-masukan yang bermanfaat bagi perbaikan artikel ini.

\section{DAFTAR PUSTAKA}

Alwi, dkk. 2003. Tata Bahasa Baku Bahasa Indonesia: Edisi Ketiga. Jakarta: Balai Pustaka

Arifuddin. 2013. "Inferring Implicatures from Short Conversations in TOEFL-LIKE: Gender-Specific and Ranking of Causes of Failure" (Surabaya: Disertasi) Universitas Negeri Surabaya Program Pascasarjana Program Studi Pendidikan Bahasa Dan sastra.

Budhiono, Ralph Hery. 2011. "YANG MANA

BAHASA IBUKU? Persaingan Pemakaian Bahasa Ibu pada Keluarga Pasangan Lintas Budaya (paper) Seminar Nasional di Universitas Udayana Bali.

Bogdan, R.C. \& Biklen, S.K. 1992. Qualitative Research for Education. An Introduction to Theory and Methods. Boston: Allyn and Bacon.

Chaer, Abdul. 2009. Psikolinguistik: Kajian

Teoretik. Jakarta: Rineka Cipta.

Clark, Herbert H., dan Eve V. Clark. 1977. Psychology and Language: An Introduction to Psycholinguistics. New York: Harcourt Brace Jovanovich, Inc.

Chomsky. 1999. On Nature, Use, And A cquisition of Language. Dalam Ritchie: Bhatia.

Chomsky \& Carol. 1969. The Acquisition of Syntax in Children From 5 to 10. Cambridge. Mass: The MIT Press.

Dardjowidjojo, Soenjono. 1983. Beberapa 
Aspek Linguistik Indonesia. Jakarta: Djambatan.

Dardjowidjojo, Soenjono. 2000. Echa: Kisah

Pemerolehan Bahasa Anak Indonesia. Jakarta:

Gramedia.

Dardjowidjojo, Soenjono. 2005. Psikolinguistik: Pengantar Pemahaman Bahasa Manusia. Edisi ke -2. Jakarta: Obor.

Dardjowidjojo, Soenjono. 2010. Psikolinguistik Pengantar Pemahaman Bahasa Manusia. Jakarta: Yayasan Obor Indonesia.

Efendi. 2012. "Pemerolehan Kalimat Majemuk Bahasa Indonesia Pada Anak Usia Taman Kanak-Kanak Aisyiyah Kecamatan Gangga Kabupaten Lombok Utara" (Tesis) Program Studi Magister Pendidikan Bahasa Indonesia Universitas Mataram.

Gustianingsih. 2002 "Pemerolehan Kalimat Majemuk Bahasa Indonesia pada Anak Usia Taman Kanak-Kanak", (Tesis) Program Pascasarjana USU.

Hidayat, A. F. dan Elis N. Rahmani. 2006. Ensiklopedi Bahasa-bahasa Dunia: Peristilahan dalam Bahasa. CV Pustaka Gravika.

Kiparsky, Paul. 1986. Linguistic Universals and Linguistic Change. New York: Halt, Rinehart and Winston.

Kridalaksana, Harimurti. 1982. Kamus Linguistik. Jakarta : Gramedia.

Mahsun. 2007. Metode Penelitian Bahasa: Tahapan Strategi, Metode, dan Tekniknya. (Edisi Revisi). Jakarta: Raja Grafindo Persada.

Mahsun. 2005. Metode Penelitian Bahasa. Jakarta. Rajawali Pres.

Mar'at, Samsunuwiyati. 2005. Psikolinguistik suatu Pengantar. Bandung: Refika Aditama.

Mbete, Aron Meko. 2007. "Bahasa Ibu: Problematika, Fungsi, Kondisi, dan Ancangan Revitalisasinya" dalam Bahasa Ibu Fungsi, Kondisi, Revitalisasi: Pemberdayaan Bahasa Indonesia dan Bahasa-Bahasa Nusantara sebagai Bahasa Ibu. Denpasar: Udayana University Press.

Parimartha, I.Gde. 2002. Perdagangan dan Politik di Nusa Tenggara 1825-1915. Jakarta: Perwakilan KITLV Djambatan.
Pateda, Mansoer. 1998. Aspek-aspek Psikolinguistik. Jogjakarta: Nusa Indah.

Porter, BD \& Hernacki, M. 2002. Quantum Learning. Membiasakan Belajar Nyaman dan Menyenangkan (diterjemahkan dari judul asli Quantum Leraning: Unleashing the Genius In You oleh Alwiyah Abdurrahman). Bandung: Kaifa.

Ridwan, T. Amin. 1999. Psikolinguistik. Medan : Pascasarjana USU.

Sampson, Geoffrey. 1980. Schools of Linguistics: Competition and Evolution. London: Hutchinson \& Co.

Steinberg, Danny D., Hiroshi Nagata, dan David P. Aline. 2001. Psycholinguistics: Language, Mind, and World. London: Longman.

Sukamto, Katharina Endriati (peny.). 2004. Menabur Benih Menuai Kasih: Persembahan 75 Tahun Anton $M$. Moeliono. Jakarta: Obor.

Sukri,Muhammad. 2009. "Ancaman Bahasa Media Elektronik Terhadap Bahasa Ibu: Kajian Mediamorfosis" (Makalah) disajikan pada Seminar Nasional Bahasa Ibu II, 27 dan 28 Februari 2009, di Denpasar, dilaksanakan oleh Program Pascasarjana Magister dan Doktor Linguistik Universitas Udayana.

Yusuf, L.N.S 2005. Psikologi Perkembangan Anak dan Remaja. Bandung: PT. Remaja Rosdakarya. 